\title{
Cutaneous Angiosarcoma of Scalp: A Case Report
}

\author{
Sunita Meena ${ }^{1}$, S R Negi ${ }^{2}$, Kishore Khatri ${ }^{3}$ \\ ${ }^{1}$ Senior resident, Department of Pathology, Dr S. N. Medical College, Jodhpur (Rajasthan) \\ ${ }^{2}$ Professor, Department of Pathology, Dr S. N. Medical College, Jodhpur (Rajasthan) \\ ${ }^{3}$ Assistant Professor, Department of Pathology, Dr S. N. Medical College, Jodhpur (Rajasthan)
}

\begin{abstract}
Cutaneous angiosarcoma is a rare vascular tumour especially of elderly males. We present a case of 45 yr male who presented with scalp lesion. It was diagnosed as cutaneous angiosarcoma on biopsy and subsequently confirmed on IHC. It attempts to alert the clinicians of this entity, as early diagnosis of the tumour may possibly improve the already known dismal prognosis.
\end{abstract}

Keywords: Biopsy, Angiosarcoma, Immunohistochemistry (IHC), scalp lesion

\section{Introduction}

Angiosarcomais a rare extremely malignant soft tissue sarcoma of endothelial origin.It constitutes $<1 \%$ of all soft tissue sarcomas and $<0.1 \%$ of all head \& neck cancers. Cutaneous Angiosarcoma is the most common presentation of this neoplasm which is usually seen in head, face \& neck of elderly patients.It is an aggressive tumor with progressive local invasion \& early metastasis .It attempts to alert the clinicians about this entity, as early diagnosis of the tumour may possibly improve the prognosis.

\section{Case Report}

A 45 year old man presented with $3 \times 2.5 \mathrm{~cm}$. Multiple reddish, indurated, hyper pigmented, erythematous pitting plaques over right frontal region of the scalp from last 15 days. Systemic examination was within normal limits. Routine investigations, Chest X-ray, USG abdomen, ECG and ECHO were normal. HIV test was negative.

Punch biopsy from the site revealed atrophic changes of epidermis, with invasive tumour in dermis made up of numerous, irregular,anastomosing vascular spaces with a distinctive dissecting pattern between collagen bundles A meshwork of vessels with their endothelial cells showing oval to elongated hyperchromatic nuclei and moderate to marked nuclear atypia. Pleomorphic and hyperchromatic spindle shaped cells with dilated and congested vascular channels dissecting the collagen were also seen in interstitial tissue [Fig:1] .Intraluminal papillary projections \& free lying malignant cells were also present. Tumor was positive for positive for CD-34[Fig:2], Vimentin[Fig:3] , MIB-1 index 20-25\% (highly proliferative ) [Fig:5] and Factor VIII showed focal positivity[Fig:4]. The histological and immunohistochemical features were suggestive of cutaneous angiosarcoma.

\section{Discussion}

Angiosarcomas are rare neoplasms accounting for less than $0.1 \%$ of head and neck malignancies ${ }^{1}$. Cutaneous angiosarcoma of the scalp and face is the most common form of angiosarcoma. Our patient also presented with scalp lesions. Case reports of eyelid and periocular lesions have been reported but are rare $^{2}$. Etiology of cutaneous angiosarcoma is unclear but may be related to previous radiation exposure, chronic lymphedema ${ }^{3}$ and after trauma ${ }^{4}$. However in our case there was no such history. Angiosarcoma is a fast spreading tumour with the highest rate of lymph node metastasis among all soft tissue sarcomas of the head and neck. Late diagnosis may be a possible reason for poor prognosis of the disease. Early detection by means of biopsy offers the only realistic chance of a cure ${ }^{5}$. Diagnosis is based on the microscopic features, ultrastructural and histochemical markers.The optimal treatment for angiosarcoma of the skin involves complete surgical resection, followed by local radiation therapy. The median time of survival ranges from 15-24 months, with a 5year survival rate of $12-33 \%$. Findings of significantly favourable prognostic importance appear to be tumour size $(<5 \mathrm{~cm})$, complete surgical resection, and a moderate or marked lymphoid infiltrate in and around the tumour. Death can occur either from local extension or metastasis. Delayed diagnosis and treatment explain, in part, the poor prognosis of cutaneous angiosarcoma.

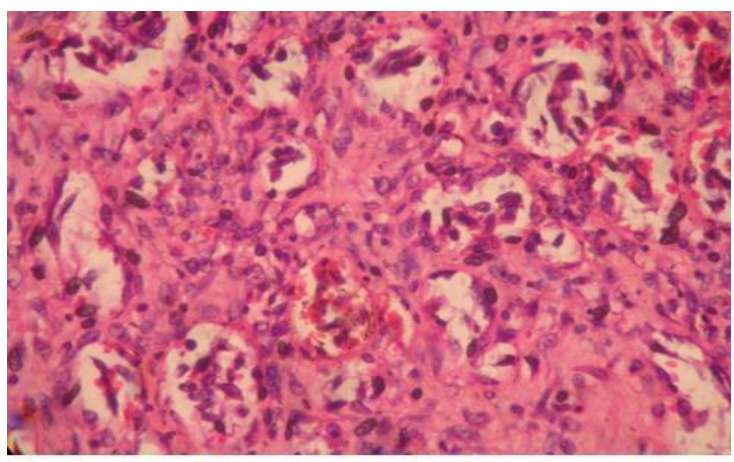

Angiosarcoma (40x)

Figure 1 


\section{International Journal of Science and Research (IJSR) \\ ISSN (Online): 2319-7064}

Index Copernicus Value (2015): 78.96 | Impact Factor (2015): 6.391

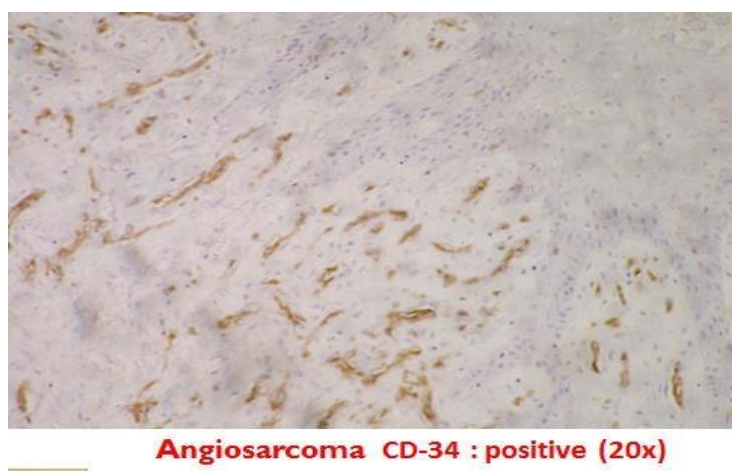

Figure 2

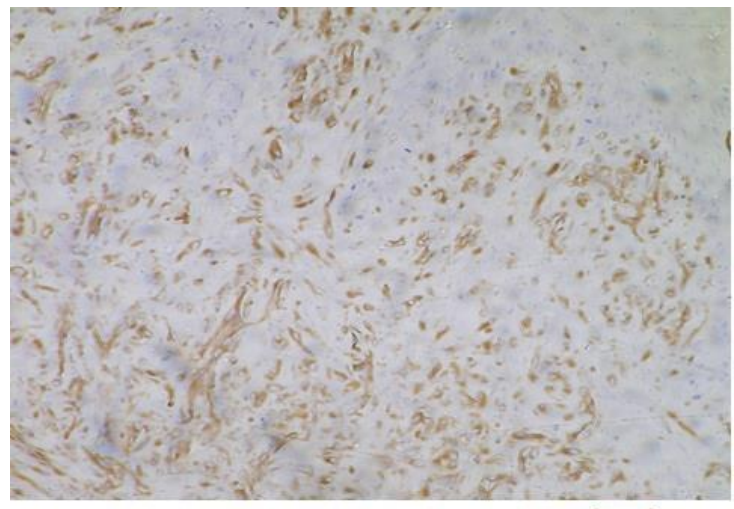

Angiosarcoma Vimentin : positive (20x)

Figure 3

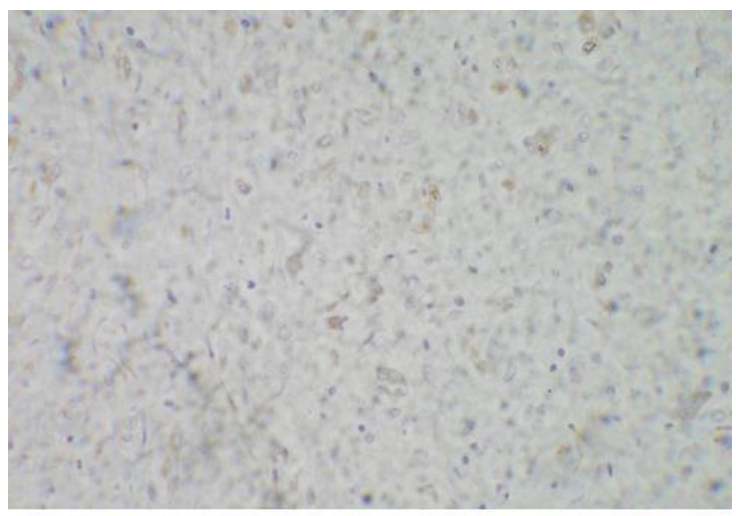

Angiosarcoma Factor VIII : focal positivity (20x)

Figure 4

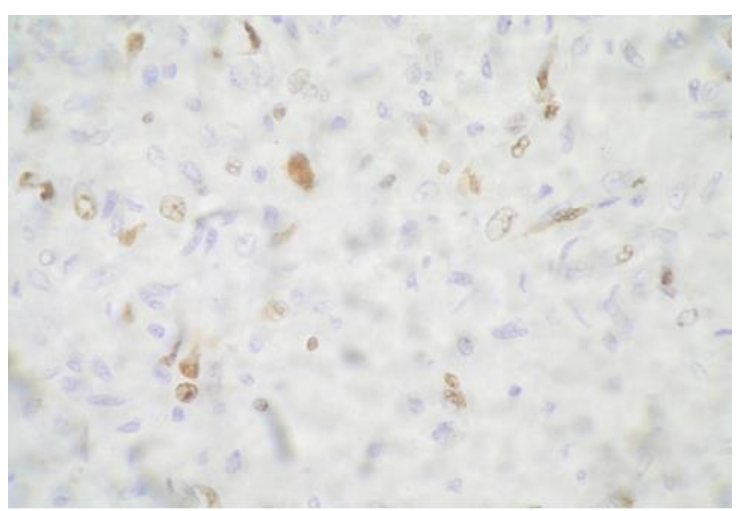

MIB-I index - 20-25\% (high proliferative ) $40 x$

Figure 5

\section{Conclusion}

The present case highlights the importance of including angiosarcoma in the differential diagnosis of all cutaneous face and scalp lesions as early diagnosis may improve the prognosis of patients.

\section{References}

[1] Sturgis EM, Potter BO. Sarcomas of the head and neck region. Curr Opin Oncol. 2003;15(3):239-52. [PubMed]

[2] Ettl T, Kleinheinz J, Mehrotra R, Schwarz S, Reichert TE, Driemel O. Infraorbital cutaneous angiosarcoma: A diagnostic and therapeutic dilemma. Head Face Med. 2008;4:18. [PMC free article][PubMed]

[3] Jonathan S Zager. Angiosarcoma of the Scalp. eMedicine. $\quad$ Retrieved 22/8/2014 fromhttp:/emedicine.medscape.com/article/1296442overview.

[4] Glickstein J, Sebelik ME, Lu Q. Cutaneous angiosarcoma of the head and neck: a case presentation and review of the literature. Ear Nose Throat J. 2006;85:672-74. [PubMed]

[5] Morgan MB, Swann M, Somach S, et al. Cutaneous angiosarcoma: a case series with prognostic correlation. J Am Acad Dermatol. 2004;50(6):867-74. [PubMed] 